\title{
EM BUSCA DE UMA TECNOLOGIA DA LIDERANÇA: MODELO MULTIPLEX
}

\author{
Artur Parreira $^{*}$ \\ *Doutor em Psicologia Social, investigador e prof. Adjunto do Mestrado em avaliação de Cesgranrio
}

Recebido em: 28/05/2014 - Aprovado em: 20/09/2014 - Disponibilizado em: 15/12/2014

\begin{abstract}
Resumo
$\mathrm{O}$ artigo apresenta um modelo de liderança de orientação tecnológica, isto é, assente na ideia de que o desempenho da liderança é um modo especifico de pilotagem do sistema humano, intencionalmente concretizável através de comportamentos definidos e com normas específicas para a sua prática. Assim, são apresentados os axiomas do modelo, identificam-se as competências requeridas para a liderança, as suas atividades próprias e os instrumentos de que o líder dispõe para as executar. Apresentam-se critérios para opção do modo liderança, em relação aos tipos fundamentais de tarefa, à posição na estrutura e a três contextos onde a liderança é exercida. $\mathrm{O}$ artigo termina com uma proposta de estudo empírico dos critérios de análise da liderança cnstitutivos do modelo.

Palavras chave: modo liderança; modo gestão; complexidade; sistema humano; competências.
\end{abstract}

\begin{abstract}
This paper presents a model of leadership, technology driven, ie, based on the idea that leadership performance is a specific way of governing the human system, intentionally achievable through defined behaviors and specific standards for practice.

Thus, the axioms of the model are defined, the competencies required for leadership are identified, as well as the activities and tools that the leader has to perform.

The author proposes four criteria for the efficacy of the leadership mode option, related to the fundamental task types, the structure and position, and three contexts in which leadership is exercised.

The paper concludes with a proposal for na empirical study of the criteria which constitute the model.

Key words: Leadership mode; management mode; complexity; human system; competences.
\end{abstract}

\section{A natureza da liderança}

A reflexão sobre a natureza da liderança vem de longe e produziu muitos conceitos e modelos teóricos. Este artigo focará a atenção diretamente na atividade onde o processo de liderança, tal como outros conceitos afins, se integra: a atividade de pilotagem de sistemas de ação complexos (Morin, 2005). A ação de pilotagem é aqui definida como o processo básico de condução e governo do sistema humano; a liderança, como a gestão ou chefia, é um modo de exercer a ação de pilotagem do sistema humano.

Weber (1947) ligava a liderança à autoridade, que é um processo de relação humana, e não ao mero poder, um recurso claramente independente dessa relação; seguiram-no muitos autores que depois dele abordaram direta ou indiretamente o conceito, como Parsons (1969), que o definia como crédito concedido a um agente decisor, ou House e Baetz (1979), que acentuam a ideia de que a liderança 
implica, por definição, relações interpessoais.

O conceito de gestão tem essencialmente o mesmo conteúdo do conceito de liderança instrumental: planear, organizar, dirigir e controlar o trabalho dos colaboradores, como salientaram os estudos que depois de Lewin (1939) foram levados a efeito na Universidade de Ohio (Stogdill e Coons, 1957) e na Universidade Michigan (Likert, 1954). É um padrão de comportamento focado na gestão dos recursos materiais e procedimentos derivados, como já Parsons (1951) salientava e neste artigo é designado como modo gestão. As competências que asseguram a eficácia da liderança são aparentadas ao que os investigadores de Ohio designaram de consideração: confiança mútua, respeito pelas ideias dos subordinados e consideração por eles. (Fleishman e Burt, 1955; Halpin e Winer, 1957; Fleishman e Peters, 1962). Neste artigo é designado de modo liderança. $\mathrm{O}$ artigo visa construir um modelo tecnológico do processo de liderança, a partir da clarificação dos dois conceitos e distinção das competências requeridas pelos dois modos.

\section{Quadro 1 - Dois modos básicos de pilotagem dos sistemas humanos}

\section{Pilotagem, governança: atividade / função essencial ao sistema humano}

\section{1b. Modo gestão}

Pilotagem focada no aproveitamento e controle dos recursos materiais, predomínio das normas, da estrutura e dos papéis desempenhados, postura impessoal.

Fonte: elaboração do autor

As competências do modo gestão estão em consonância com a perspetiva e regras das organizações tradicionais, (UBBEN \& HUGHES, 1987), e por isso Burns (1978) o designou como transacional. O modo liderança de pilotagem é baseado em relações personalizadas, está atento principalmente aos colaboradores, para lhes incutir a visão do que a organização deve ser e levá-los a concretizá-la. Foi o que levou Burns a designar os líderes de transformadores.

\section{1a. Modo liderança}

Pilotagem focada na construção do sistema humano, predomínio das relações e da comunicação, modo informal e personalizado de interação.
A pilotagem de um sistema humano exige fundamentalmente que o piloto assuma uma relação com o sistema como tal e não apenas com aspetos particulares dele; por isso, os dois modos de pilotagem têm naturalmente de lidar com os processos materiais e humanos da organização (ZALEZNIK, 1992), para responder com eficácia às exigências colocadas pelo contexto. O importante a reter, no entanto, é que a visão global do sistema no modo gestão assenta na definição das operações, 
recursos e metas; o modo liderança constrói essa visão global com base na relação com o grupo, a quem propõe uma identidade e um destino comum, com metas e recursos partilhados. Esta visão e relação global personalizada é o cerne do modo liderança, é ela que o distingue do modo gestão e o torna especialmente adequado à pilotagem de sistemas humanos.

Neste artigo apresenta-se um modelo tecnológico de liderança designado de Multiplex - em recordação do termo usado por Edgar Morin (1995), num dos seus escritos sobre o desafio da complexidade. Um segundo artigo tratará de testes empíricos do modelo.

\section{O Modelo Multiplex}

Primeiro postulado: $a$ pilotagem de um sistema humano realiza-se através de dois tipos fundamentais de atividades: dinamização e controle. Para a sua realização eficaz, cada tipo de atividades requer competências próprias de cada modo de pilotagem.

\section{Quadro 2- Atividades de dinamização e controle}

\begin{tabular}{|l|l|}
\hline Atividades de dinamização & Atividades de controle \\
\hline - Definir metas aliciantes, motivar para agir & - Definir e realizar controles financeiros e \\
numa determinada direção; & controles de qualidade; \\
- Criar um clima positivo e uma cultura & - Avaliar o desempenho: organizacional, \\
dinâmica; & de equipas e de colaboradores \\
- Delegar poderes de decisão e ação; & - Avaliar e controlar as condições \\
- Dar incentivos e recompensas; & das estruturas de trabalho \\
- Dar exemplo positivo, fomentar o & - Definir e realizar o controle dos \\
desenvolvimento de competências, a & processos de trabalho. \\
inovação e as mudanças positivas; & \\
- Fazer circular as informações úteis, criar & \\
sinergia de operações. & \\
\hline
\end{tabular}

Fonte: Elaboração do autor

As atividades de controle estão mais orientadas para organização de operações e recursos; requerem, por isso, competências mais associadas ao modo gestão da pilotagem: o sistema humano aparece como um tem que ser, como uma condição necessária com a qual tem de se lidar, mas cuja característica é ser difícil de manejar.
As atividades de dinamização assentam em competências características do modo liderança: focam o piloto na condução do sistema humano, e é através do sistema humano que os recursos são organizados e aproveitados. O controle dos recursos materiais aparece como secundário e, por isso, é às vezes descurado. 
Quadro 3. Competências nucleares dos dois modos de pilotagem

\begin{tabular}{|l|l|}
\hline Competências do modo gestão & Competências do modo liderança \\
\hline Organização de meios & Influência e persuasão \\
Análise cognitiva & Criação de metas atrativas \\
Definição e imposição de normas & Proposta de modelos a seguir \\
Definição de estruturas & Escuta ativa \\
Planeamento de atividades & Criação de visões positivas \\
Controle de processos & Atratividade pessoal \\
Garantia de homogeneidade & Aproveitamento da diversidade \\
A norma é o sentido da eficiência & Indução do senso da grandeza \\
\hline
\end{tabular}

Fonte: Elaboração do autor

Segundo postulado: Há critérios objetivos

para determinar a combinatória de competências e, portanto, o modo de pilotagem mais

adequado em cada situação.

\section{Quadro 4. Critérios para combinatórias adequadas (Modelo Multiplex)}

1. Complexidade: Quanto maior a complexidade do sistema, maior a necessidade do modo liderança

2. Posição na estrutura: Quanto mais alta a posição na estrutura, maior a complexidade das ações e decisões, e maior a necessidade do modo liderança

3. Tipo de tarefa: Quanto mais as tarefas exigirem envolvimento dos colaboradores, maior a necessidade do modo liderança

4. Tipo de contexto: Quanto mais o contexto for móvel e maior for a variedade externa maior a necessidade do modo liderança.

Fonte: Elaboração do autor

Os critérios enunciados - relacionados todos com os desafios derivados da complexidade das situações - permitem decidir em que medida a pilotagem deve assentar no modo liderança.
Critério complexidade - Quanto maior a complexidade do sistema, maior a necessidade das competências da liderança e, portanto, do modo liderança na pilotagem (Goldstein, 2005).

Quadro 5. Fatores para medir a complexidade de um sistema humano

\begin{tabular}{|l|l|}
\hline $\begin{array}{l}\text { 1.Nível de pensamento } \\
\text { e de informação }\end{array}$ & $\begin{array}{l}\text { Nível de pensamento praticado no sistema humano, grau de } \\
\text { abertura à entrada de informação, nível de conhecimento } \\
\text { demonstrado (Le Moigne, 1999). }\end{array}$ \\
\hline $\begin{array}{l}\text { 2. Variedade interna do } \\
\text { sistema }\end{array}$ & $\begin{array}{l}\text { Diversificação das vivências que o sistema interpreta e constrói; } \\
\text { grau de diversidade do seu leque de competências (Simon, H., } \\
1987)\end{array}$ \\
\hline $\begin{array}{l}\text { 3.Variedade externa do } \\
\text { sistema }\end{array}$ & $\begin{array}{l}\text { Diversidade das entidades com as quais o sistema tem relações } \\
\text { continuadas e dos tipos de competências postas em ação nessas } \\
\text { relações (Vaz, 2003). }\end{array}$ \\
\hline
\end{tabular}




\begin{tabular}{|l|l|}
\hline $\begin{array}{l}\text { 4. Integração } \\
\text { informacional da } \\
\text { variedade }\end{array}$ & $\begin{array}{l}\text { Integração da diversidade de estruturas, processos e comportamentos: } \\
\text { combinação de coerência e flexibilidade, variedade de opções de } \\
\text { ação. Lidar bem com a incerteza, não estar restrito ao raciocínio } \\
\text { determinista (Le Moigne, 2011). }\end{array}$ \\
\hline
\end{tabular}

Fonte: Elaboração do autor

\section{Critério 'posição na estrutura' - O Modelo} considera três níveis de posição estrutural, nos sistemas complexos de ação, cada um deles requer competências específicas em prontidão.

A posição na estrutura da organização define o nível da pilotagem, mesmo nas organizações que se estruturam em rede: como Dahrendorf (1971) acentuou, continuam a ser sistemas imperativamente coordenados. É a extensão abrangida pelos atos de decisão e de controle que define o nível da posição na estrutura.

Níveis de posição considerados no Modelo: posição estratégica, em que as decisões e ações visam a globalidade do sistema humano; posição tática, em que as decisões e ações visam setores amplos do sistema, com objetivos específicos; posição operacional, em que as decisões e ações se focam em operações concretas.

Critério 'tipo de tarefa' - $O$ Modelo considera quatro tipos básicos de tarefa, cada um com

as suas exigências de atitude $e$ competências específicas a serem postas em prática pelo piloto do sistema. a. Produzir ideias, explorar de perspectivas pelos membros do sistema;

b. Persuadir os colaboradores do sistema;

c. Tomar decisões a cargo dos órgãos de pilotagem do sistema;

d. Aumentar a coesão do sistema humano, a positividade do clima.

As atividades de produção de ideias, persuasão e coesão do sistema são fortemente sensíveis às competências nucleares do modo liderança.

A tomada de decisões é mais independente das competências de liderança, já que a organização e o controle são importantes nessa tarefa; ainda assim, a escuta ativa, a criação de visões positivas e o senso da grandeza têm igualmente relação bastante forte com a qualidade das decisões, principalmente ao nível estratégico.

Critério 'tipo de contexto' - O Modelo considera três tipos de contexto: produtivos, formativos, políticos. A mobilidade e a variedade interna e externa são os critérios definidores da necessidade do modo liderança.

No contexto produtivo, o sistema humano visa criar riqueza, em situação de competição por recursos escassos. O foco 
temporal é principalmente o curto e o médio prazo; a tarefa crucial é tomar decisões geradoras de riqueza.

Nos contextos formativo e político, as atividades são predominantemente relacionais (Rato, 2010): requerem sobretudo competências como a escuta ativa, a negociação, a atratividade pessoal (carisma), a visão criativa.

Ajustar o tipo de liderança ao contexto é, pois, o primeiro cuidado do piloto:

- praticar uma liderança sinérgica nos contextos de produtividade;

- praticar uma liderança transformadora (Burns, 2004), nos contextos de desenvolvimento;

- ter uma liderança visionária e carismática, nos contextos de ação política.

Terceiro postulado: Para realizar os dois tipos de atividades da pilotagem dinamização e controle - tendo em conta a posição, as tarefas e o contexto - o líder tem dois instrumentos à disposição: informação e poder.

\section{A ferramenta poder}

O poder é a aplicação de energia (motivação, emoção) para condicionar o comportamento dos colaboradores (Parreira, 2006); a informação é a transmissão de significados que influem nas suas representações $d a$ realidade (Whetten e Godfrey,1998). Como energia, o poder varia de intensidade: elevado poder; médio poder; baixo poder; e a intensidade do poder resulta da combinação dos tipos de poder com a frequência do seu uso.

Os tipos de poder, uma dimensão qualitativa, são descritos com base nas categorias adaptadas de Etzioni (1984): coercivo (ameaça, punição); manipulativo (promessa); e assertivo (disponibilização de recursos).

O modo liderança utiliza mais pensadamente poder e informação na relação com os colaboradores; o modo gestão, ao basear extensamente a sua ação em estruturas e normas, acaba por utilizar muito do poder ínsito nelas, sem mesmo se aperceber disso (Pina e Cunha, 2006; Parreira, 2010).

\section{A ferramenta informação}

Enquanto o poder move o comportamento pela sua condição de energia, a informação move-o por ser transmissão de significados, que definem os objetos desencadeadores de emoção (energia) no sujeito. $\mathrm{O}$ conceito de informação proposto no Modelo Multiplex fundamenta-se, por um lado, nos estudos da Escola de Palo Alto, apresentados em Drucker (1972); e, por outro nos dois estilos de comunicação negocial que Deutsch (1973) designou de competitivo e resolutivo, e a cuja descrição Parreira (1983) adaptou as categorias de E. Porter (1950), para medir o uso da informação pelo líder. Porque o importante para 
decidir e agir é a informação, que é

significado; mas sem comunicação, sem a

atribuição de significado pelo receptor, não

há informação, há apenas ruído.

\section{Quadro 6. Estilos de comunicação,} segundo Deutsch e Porter ${ }^{1}$

\begin{tabular}{|c|c|}
\hline Estilo competitivo (Deutsch) & Indicadores atitudinais (Porter) \\
\hline $\begin{array}{l}\text { - Escassez de comunicação; informações enganadoras; } \\
\text { - Sensibilidade predominante para as ameaças e } \\
\text { diferenças } \\
\text { - Percepção dicotómica do espaço de valores: } \\
\text { (bons / maus, sem matizes) } \\
\text { - Desconfiança do interlocutor, exploração de seus } \\
\text { pontos fracos } \\
\text { - Ideia de que o conflito só se pode resolver por } \\
\text { imposição de força. }\end{array}$ & $\begin{array}{l}\text { Predomínio de atitudes } \mathbf{A V} \text { e } \mathbf{O} ; \\
\text { - Fraca presença de atitudes } \mathbf{E} \text { e } \mathbf{R}, \\
\text { e mesmo A ; } \\
\text { - Percepção parcelar do outro } \\
\text { (como manipulável); } \\
\text { - recurso frequente aos tipos de } \\
\text { poder coercivo e manipulativo. }\end{array}$ \\
\hline Estilo resolutivo (Deutsch & Indicadores atitudinais (Porter) \\
\hline $\begin{array}{l}\text { - Troca de informações relevantes } \\
\text { - Sensibilidade às semelhanças e à complementarização } \\
\text { de esforços } \\
\text { - Percepção matizada do espaço de valores: } \\
\text { - Confiança, não aproveitar os pontos fracos do } \\
\text { interlocutor } \\
\text { - Ideia de que o conflito é inteligível e de que negociar } \\
\text { o instrumento indicado para o resolver. }\end{array}$ & $\begin{array}{l}\text { - Uso extenso de atitudes: A, E e R; } \\
\text { - percepção do outro como pessoa } \\
\text { (capaz de esclarecimento mútuo) } \\
\text { - percepção matizada e policêntrica } \\
\text { do espaço valorativo } \\
\text { - recurso predominante ao poder } \\
\text { assertivo. }\end{array}$ \\
\hline
\end{tabular}

Fonte: Parreira (2010)

Para usar a informação como ferramenta

da pilotagem, o líder precisa de utilizar o

${ }^{1}$ Neste trabalho foi utilizada a seguinte adaptação das categorias de Porter:

Atitude de avaliação (AV) - expressões de repreensão, censura, punição, desvalorização, discordância;

Atitude de orientação $(\boldsymbol{O})$ : ordens, orientações, opiniões, conselhos, sugestões informações;

Atitude de apoio $(\boldsymbol{A})$ - concordância com ideias e opiniões do outro; expressões de simpatia;

Atitude exploratória da informação (E) pergunta direta ou indireta, afirmações sobre a própria carência de

informação;

Atitude de reformulação, compreensão ou empática $(\boldsymbol{R})$ - reformular é repetir o conteúdo ou o sentimento

expresso pelo interlocutor, com palavras similares. estilo de interação resolutivo com à ontade: escuta ativa, aproveitamento das informações produzidas pelos interlocutores, explicitação de objetivos comuns (Canegallo et al., 2007): desta forma, o uso do estilo resolutivo garante a comunicação e, portanto, a informação. Esses estilos estão explicitados nos quadros 5 e 6 . 


\section{O uso tecnologicamente orientado da}

informação e do poder pelo líder

Em primeiro lugar, para usar o poder como ferramenta, é fundamental saber manifestar os vários tipos de poder, em termos de intensidade, a qual resulta da combinação dos tipos de poder com a frequência do seu uso.

$\mathrm{O}$ uso do poder serve essencialmente para controlar; para dinamizar pessoas e as equipas, o líder tem de apostar no uso extensivo da informação. Saber usar o poder (tipo e intensidade) e os estilos de comunicação é, assim, crucial para uma liderança tecnologicamente orientada. Mas o poder e a informação variam na razão inversa; consequentemente, a relação entre dinamização e controle obedece a um curva similar (Parreira et al., 2014), como se mostra no gráfico 1 .

\section{Gráfico 1. Curva da relação entre dinamização e controle}

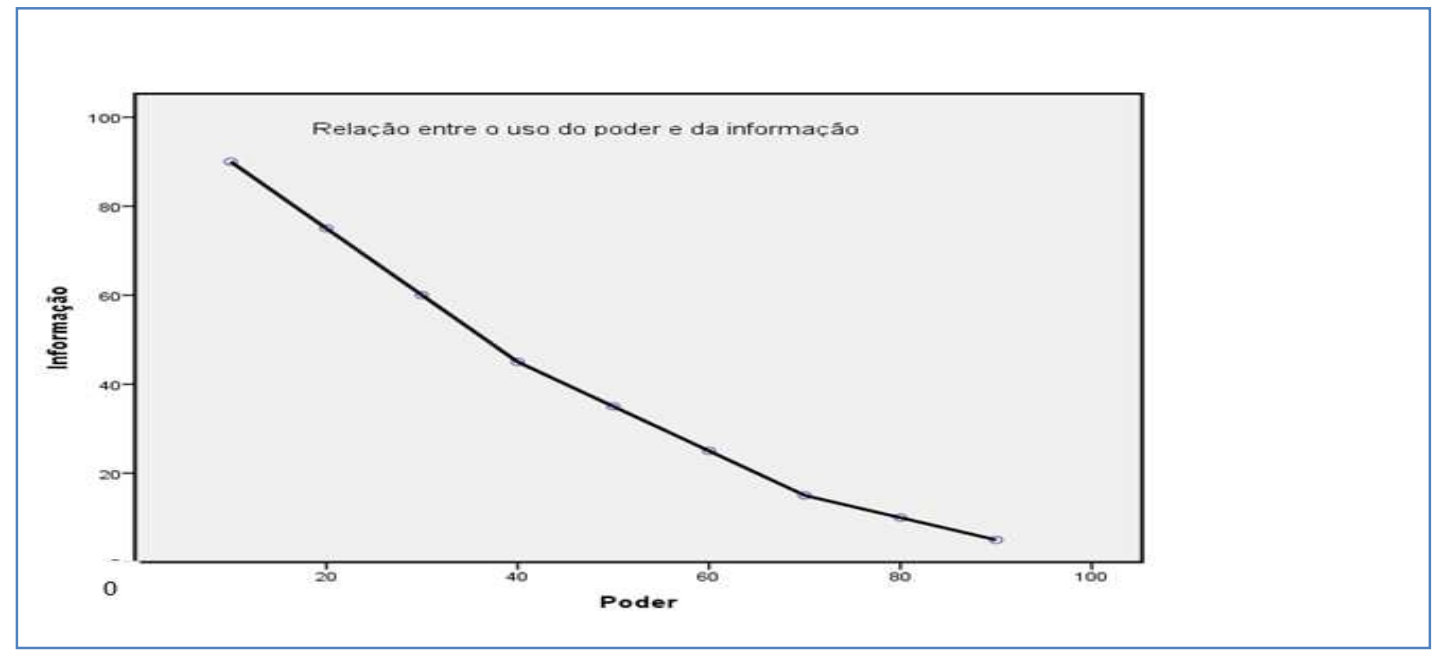

Fonte: Parreira, Lorga da Silva e Elliot (2014)

Para dinamizar as pessoas e as equipas, o líder tem de apostar no uso extensivo da informação; mas, para isso, tem de reduzir o uso do poder, pois o uso do poder restringe a informação e, consequentemente, o seu efeito dinamizador. Para ampliar o uso da informação, é necessário generalizar a prática do estilo resolutivo de interação (bastando para atingir esse objetivo o treino eficaz dos líderes da organização na prática desse estilo).
Reduzir o uso do poder é um resultado que se obtém por delegação consistente e por redução do uso dos rituais e símbolos culturais reforçadores do uso do poder.

O recurso ao poder só é recomendado no Modelo Multiplex, quando se quer obter um efeito de controle rápido; mas o líder sabe que isso reduz o efeito de dinamização. A informação também pode ser usada como instrumento de controle - autocontrole, nesse 
caso: as equipas mantêm a flexibilidade e mobilidade, mas surgem mais facilmente falhas, que terão de ser corrigidas.

Quinto postulado: Para concretizar a combinatória de competências exigidas pelo modo liderança, o piloto do sistema tem de desenvolver três tipos de competências fundamentais (já propostas por Robert Katz em 1974): elas são a condição necessária para escolher as combinatórias baseadas nos critérios enunciados acima.

Quadro 3. A tripla competência e a eficácia da pilotagem (adaptado de Katz)

\begin{tabular}{|l|l|}
\hline $\begin{array}{l}\text { Competência } \\
\text { técnica (T) }\end{array}$ & $\begin{array}{l}\text { A competência técnica assegura as competências de organização de meios e } \\
\text { eficiência da execução: fazer bem feito, de acordo com as normas de } \\
\text { qualidade, aquilo que tem de se fazer. } \\
\text { - }\end{array}$ \\
\hline $\begin{array}{l}\text { Competência } \\
\text { interpessoal (I) }\end{array}$ & $\begin{array}{l}\text { Criar relações positivas e verdadeiras: desenvolver na relação emoções e } \\
\text { sentimentos positivos, abertos e agradáveis; manter elevado nível de } \\
\text { verdade nas relações: é a prática de um estilo de comunicação resolutivo } \\
\text { (Deutsch, 1973) que assegura um nível elevado desta competência. }\end{array}$ \\
\hline $\begin{array}{l}\text { Competência } \\
\text { estratégica (E) }\end{array}$ & $\begin{array}{l}\text { Tomar decisões eficazes e oportunas, saber conceptualizar as situações e } \\
\text { elaborar projetos; uso inteligente do poder e da informação nas relações } \\
\text { com o sistema humano e na ação. }\end{array}$ \\
\hline
\end{tabular}

Fonte: Elaboração do autor

O domínio destas competências pode ser conseguido através de instrumentos formativos e de mudança, como coaching, a experiência refletida, o estudo de modelos e assimilação de seus padrões de comportamento.

\section{A pilotagem no modo liderança}

A capacidade de escolher diferentes combinatórias, de acordo com as variáveis da situação, define o grau de flexibilidade da liderança, uma perspectiva contingencial do desempenho do líder (Fiedler e Garcia, 1987; Hersey e Blanchard, 1976), fundamental para a adequação das práticas do líder às pessoas e situações.

\section{Estilos de liderança e flexibilidade}

A flexibilidade do comportamento de liderança é uma recomendação fundamental no Modelo Multiplex. De facto, a flexibilidade é a forma de o líder responder à variedade e complexidade das situações que o sistema humano enfrenta e adotar o padrão de liderança adequado, de acordo com os critérios apresentados acima. É definida pela combinatória de poder e informação que o líder escolhe: ou espontaneamente, de acordo com suas experiências de vida, ou tecnologicamente, 
de acordo com os critérios do modelo

Multiplex, aqui proposto: a flexibilidade é definida pela combinação de maior ou menor quantidade de poder com o estilo resolutivo de comunicação.

Quadro 5. A flexibilidade na liderança: três tipos de estilos intencionais

\begin{tabular}{|l|l|}
\hline $\begin{array}{l}\text { Índices qualitativos } \\
\text { (manter) }\end{array}$ & Índices quantitativos (variar) \\
\hline & $\begin{array}{l}\text { A - Participativo musculado } \\
\text { Uso de poder elevado (para situações em que um estilo de tipo } \\
\text { autoritário é desejável). Os liderados sentem-no como autoritário aberto. }\end{array}$ \\
\hline $\begin{array}{l}\text { Estilo de interação } \\
\text { resolutivo }\end{array}$ & $\begin{array}{l}\text { B - Participativo franco } \\
\text { Uso de poder médio (para situações em que um estilo de tipo claramente } \\
\text { participativo é recomendável. Os liderados sentem-no como aberto e } \\
\text { confiável. } \\
\text { C - Liberal } \\
\text { Uso de baixo poder (para situações em que um estilo de tipo laissez- } \\
\text { faire é aceitável). Os liderados sentem-no como aberto e descontrativo. }\end{array}$ \\
\hline
\end{tabular}

Num artigo posterior, serão apresentados os dados de uma pesquisa em que foi testado o Modelo e seus pressupostos.

Referências

BURNS J.M. (1978) Leadership. New

York: Harper \& Row (2004). Transforming

Leadership. Grove Press

CANEGALLO, C., ORTONA, G., PAZARO F. \& SCACIATI F. (2007).

Competition versus Cooperation: Some

Experimental Evidence. Elsevier

DAHRENDORF, R. (1959) Class and Class Conflict in Industrial Society.Stanford: Stanford University Press.
DEUTSCH, M. (1973) The Resolution of

Conflict: Constuctive and Destructive

Processes. Yale Univ. Press.

DRUCKER , P. (1972) Tecnologia,

Gerência e Sociedade. R. Janeiro: Vozes

ETZIONI, A. (1984, ed. brasileira) Análise Comparativa das Organizações Complexas. Rio de Janeiro: Zahar

FIEDLER, F. \& GARCIA, J.L. (1987)

New Approaches to Effective Leadership:

Cognitive Resources and Organizational

Performance. N. York: Wiley

FLEISHMAN, E. A. \& BURT, H.E. (1955) Leadership and Supervision in Industry. Columbus, Ohio: Ohio Univ. Press.

FLEISHMAN, E.A. \& PETERS, D.R. (1962) Interpersonal Values, Leadership 
Attitudes and managerial Success.

Personnel Psychology, 15, 127-143.

FRENCH, J. \& RAVEN, B. (1958) The

Bases of Social Power. In: Cartwright,D.

(ED.) Studies in Social Power. Ann

Harbor: Univ. Michigan Press

GOLDSTEIN R. (2005) Incompletude - A

Demonstração e o Paradoxo de Kurt

Gödel. Lisboa: Gradiva

HALPIN, A.W. \& WINER, B.J. (1957). A factorial study of the leader behavior descriptions. IN. STOGDILL, R.M \& COONS A.E. (Eds), Leader behavior:Its description and measurement. Columbus, $\mathrm{OH}$ : Ohio State University Bureau of Business Research.

HERSEY, P. E BLANCHARD, K. (1969).

Life-cycle Theory of Leadership. Training and Development Journal, 23, 26-34

HOUSE, R. \& BAETZ, H. (1979). Leadership: Some empirical generalizations and new research directions. In: B. Saw (Ed.) Research in Organizational Behavior (Vol. I). Greenwich, Connecticut: JAI Press.

KATZ, R.L. (1974) Skills of an Effective Administrator. Harvard Business Review (HBR Classic)

LE MOIGNE (1999) Inteligência da Complexidade, in: Pena, A. (1999) O pensar Complexo. Rio de Janeiro:

Garamond

\footnotetext{
Revista da Universidade Vale do Rio Verde, Três Corações, v. 12, n. 2, p. 852-863, ago./dez. 2014
} 
PARSONS, T. (1951). The Social System. Glencoe: Free Press. (1969).Politics and Social Structure. Glencoe: The Free Press.

PINA E CUNHA, M., REGO,A., CAMPOS E CUNHA, R. \& CABRAL CARDOSO, C. (2007) Manual de Comportamento Organizacional e Gestão. Lisboa: RH Editora.

PORTER, E.H. (1950) An Introduction to

Therapeutic Counseling. Boston:

Houghton Mifflin.

RATO, H. (2010). Crise e Democracia: Resolução da Crise e Aprofundamento da Democracia. In:SOUSA FERREIRA, E., OLIVEIRA, J.P. \& MORTÁGUA, M.J. Investigação e Prática em Economia. Parede: Principia

ROGERS C. (1951). Client-Centered Therapy. Boston: Houghton Mifflin.

SIMON, H. (1987) . Complexity and the Representation of Patterned Sequences of Symbols. In: Models of Thought. Yale Univ. Press

STOGDILL, R.M. \& COONS, A.E. (EDS), Leader behavior: Its description and measurement. Columbus, $\mathrm{OH}$ : Bureau of Business Research, Ohio State University

UBBEN, G., HUGHES, L., \& NORRIS, C. (1987). The principal: Creative leadership for excellence in schools Needham Heights, MA: Allyn \& Bacon.(Há uma 5 edição de 2004, com Cíntia Norris, na mesma editora)

VAZ, P. (2003) Tempo e Tecnologia. In: Tempo dos Tempos. Rio de Janeiro: Jorge Zahar Editor.

WEBER, M (1947). The Theory of Economic and Social Organization. Glencoe: Free Press.

WHETTEN, DAVID e GODFREY, PAUL (1998). Identity in Organizations: Building Theory through Conversations. EnglewoodCliffs: Prentice-Hall

ZALENIK, A. (1992). Managers and leaders: are they different? Harvard Business Review. Março/Abril, p 126. 